ORIGINAL ARTICLE

\title{
HIV/AIDS Preventive Practice and Associated Factors among Female Sex Workers in Afar Region, Ethiopia: A Community Based Study
}

\author{
Abay Woday Tadesse ${ }^{1 *}$, Wossen Chernet ${ }^{2}$, Osman Ahmed ${ }^{3}$, Woldemichael \\ Tadesse $^{3}$
}

\author{
OPEN ACCESS \\ Citation: Abay Woday Wossen Chernet, \\ Osman Ahmed. Woldemichael Tadesse. \\ HIV/AIDS Preventive Practice and \\ Associated Factors among Female Sex \\ Workers in Afar Region, Ethiopia: A \\ Community Based Study. Ethiop J Health \\ Sci. 2020; 30(1):45. \\ doi:http://dx.doi.org/10.4314/ejhs.v30 \\ i1.7 \\ Received: July 17, 2019 \\ Accepted: September 11, 2019 \\ Published: January 1, 2020 \\ Copyright: (C2020 Abay Woday, et al. \\ This is an open access article distributed \\ under the terms of the Creative Commons \\ Attribution License, which permits \\ unrestricted use, distribution, and \\ reproduction in any medium, provided the \\ original author and source are credited. \\ Funding: Nil \\ Competing Interests: The authors declare \\ that this manuscript was approved by all \\ authors in its form and that no competing \\ interest exists. \\ Affiliation and Correspondence: \\ ${ }^{1}$ Samara University, College of Health \\ Science, Department of Public Health, \\ Afar, Ethiopia \\ ${ }^{2}$ Save the Children, Semera Field \\ Office, Semera, Afar, Ethiopia \\ ${ }^{3}$ Samara University, College of Health \\ Science, Department of Nursing, Afar, \\ Ethiopia \\ *Email: abaywoday@yahoo.com
}

\begin{abstract}
BACKGROUND: Female Sex Workers (FSWs) are a high-risk population for Human Immune Virus (HIV) infection. However, HIV related services for sex workers are given little attention in developing nations like Ethiopia. Thus, this study attempted to assess HIV preventive practice and associated factors among FSWs in the Afar region.

METHODS: Community-based cross-sectional study was conducted on 419 FSWs from April $1^{\text {st }}$ to May $2^{\text {nd }}$ in 2018 in four hotspot towns (i.e. Logia, Mille, Gedamayitu and Awash) found in Afar region. The study participants were selected using snowball sampling technique. The sociodemographic and behavioral data were collected using face-toface interview. Logistic regression analyses were done to determine factors associated with HIV prevention practices. The statistically significant level was declared at a P-value $<0.05$.

RESULTS: The HIV/AIDS preventive practice among FSWs was 61.1\% [95\% CI 56.2\% - 65.9\%]. The multivariable logistic regression analysis showed that being single $[A O R=2.57: 95 \%$ CI 1.06, 6.21: $P<0.05]$ and urban residence before being $F S W s$ [AOR $=3.26: 95 \% C I$ 1.25, 8.54: $P<0.05]$ were found to be enhancing factors of the preventive practice of HIVIAIDS. However, being illiterate [AOR=0.133: 95\% CI 0.032, 0.557: $P<0.01]$, young age [AOR=0.065: 95\% CI 0.021, 0.196: $P<0.001]$, being alcohol drinker [AOR=0.104: 95\% CI 0.026, 0.417: $P<0.01]$, being cigarette smoker [AOR=0.096: 95\% CI 0.022, 0.414: $P<0.01]$ and lack of aware of HIV transmission [AOR=0.08: 95\% CI 0.03, 0.22: $P<0.001]$ were the hindering factors of the preventive practice of HIV among FSWs.

CONCLUSION: The HIVIAIDS preventive practice among FSWs in Afar region hotspot towns (61.1\%) is still very low compared to the country progress report on HIV response for FSWs (98\%). The regional health bureau should design inclusive strategies to improve the HIV preventive practice among FSWs. These includes regular HIV testing campaigns, sustainable condom distribution in the hotspot towns. The region should encourage NGOs to work on inclusive HIV prevention upon FSWs. Female sex workers should be aware of the risky behaviors that lead to HIV. Additional qualitative methods are also recommended. KEYWORDS: HIVIAIDS, preventive practice, associated factors, female sex workers, Afar region, Ethiopia
\end{abstract}




\section{INTRODUCTION}

Acquired Immunodeficiency Syndrome (AIDS) is a pandemic disease caused by Human Immunodeficiency Virus (HIV) that destructs disease resistance of the body. Consequently, it makes our body vulnerable to ordinarily innocuous infections (1).

Female Sex Workers (FSWs) are females who are involved in sex to generate income or increase their income. Moreover, FSWs are categorized as either hotel/bar-based, street-based and home-based FSWs. In developing nations, discrepancies in socioeconomic status have forced young females to be engaged in life-threatening sources of incomes including sexual trade (2-4).

In 2014, the global HIV prevalence among FSW was $11.8 \%$; the highest prevalence was found in sub-Saharan Africa countries and the burden of the diseases was expected to be optimally high in these countries in the near future $(36 \%)(4,5)$. In Ethiopia, the prevalence of HIV among the general population ranges between $0.8 \%$ and $4.8 \%$ (6). However, the HIV prevalence among FSWs $(23 \%)$ is higher than the general population prevalence $(0.9 \%)$ in the country. Its prevalence is slightly higher among FSWs residing in Afar region (26\%) (7). In addition, only $42.3 \%$ of Ethiopian female sex workers were reached by HIV prevention program. Of the $44.8 \%$ of FSWs tested for HIV, $25 \%$ were found to be HIV Positive (8). The survey conducted by Population Service International Ethiopia (PSI/E) has identified hotspot towns in Afar region. The survey found more than five thousand female sex workers residing in the seven hotspot Towns (Awash, Gedamayitu, Gewanie, Adayitu, Mille, Logia and Dichotu) of the region (3).

Studies conducted across the globe identified different factors contributing to female sex workers to be at risk for HIV infection such as having many sex partners, unsafe working conditions, alcohol drinking, cigarette smoking, drug use, physical violence, inconsistent condom use, intimate partner violence and lack of access to healthcare due to harassment from law enforcers (9-14). Different strategies, policies and programs have been tried in the past to reduce te transmission and the incidence of new cases of HIV at global, regional and national levels $(2,3,8,15)$. What remains missing is a respectful and inclusive response to marginalized and vulnerable populations including sex workers who are given little attention across the globe especially in sub-Saharan countries; the burden of HIV/AIDS is considerably 12 times higher among sex workers than the general population $(4,8,16)$.

A community-based cross-sectional study conducted in Dessie town showed that the HIV/AIDS preventive practice among FSWs was around the median (54.8\%) (17). Moreover, limited studies have been conducted todate in Ethiopia. Specifically, no study has been done in Afar region, one of the hotspot areas that need information regarding the level of preventive practice upon HIV/AIDS among FSWs. Thus, this study intended to assess the preventive practice and associated factors of HIV/AIDS among female sex workers in Afar region.

\section{METHODS AND MATERIALS}

Study setting and participants: A communitybased cross-sectional study was conducted from April $1^{\text {st }}$ to May $2^{\text {nd }}, 2018$ among female sex workers who resided in hotspot towns (i.e. Logia, Mille, Gedamayitu and Awash) of Afar region, Northeast Ethiopia. The hotspot towns are located on the main street of Addis Ababa-Djibouti high way. The towns have a total population of 431,065 . Of these, $51 \%$ are males and $49 \%$ are females (Census, 2007). There are different levels of hotels, bars, night clubs, shisha houses and local drinking houses in hotspot towns. According to the Population Service International (PSI), there are nearly five thousand Female Sex Workers (FSWs) in Afar region. In this region, FSWs have two main categories based on their working establishments. These are hotel/-bar based and home-based FSWs.

All female sex workers who are 18 years of age and above living in the selected hotspot towns were eligible for this study. However, Female sex workers who were seriously ill during the data collection period were not included.

The sample size was calculated using single population proportion formula by considering the basic assumptions of $95 \%$ Confidence interval (for the Critical value $\mathrm{Z} \alpha / 2=1.96$ ), $5 \%$ margin of error, the proportion of $54.8 \%$ taken from the previous study conducted in Dessie town for the preventive

DOI: http://dx.doi.org/10.4314/ejhs.v30i1.7 
practice of HIV among FSWs (17); the researchers also added $10 \%$ to compensate the non-responses since the issue is very sensitive and private. After adding $10 \%$ non-response rate $(381 \times 10 \% / 100=38)$, the sample size becames 419 .

Snowball sampling technique was employed because of the sensitivity of the issue, lack of recorded data that can be used as sampling frame regarding the number and list of female sex workers and difficulty of getting the number of FSWs in each town unlike that of the general population. The sample size was proportionally allocated into the four hotspot towns (namely; Logia, Mille, Gedamayitu and Awash). The initial information was taken from the index sex worker participants who were working as a peer educator in the nongovernment organization entitled "Beza HIV Care Association" which was working in the four towns during the data collection period. After getting the first participant, information was taken to get the next participants (chain referral way). Therefore, FSWs were recruited in this way until the desired sample size was satisfied.

Data processing and analysis: Standardized, pretested and structured interviewer-administered questionnaire was used to assess the preventive practice of HIV/AIDS and associated factors among FSWs. The questionnaire consists of sociodemographic, behavioral factors, Knowledge of HIV and preventive practice of HIV related questions. The tool was pretested in Asayita town on $5 \%$ of the sample to address any unclear or misunderstood questions, and some amendments were made based on the pretest findings.

The data was collected by six trained BSc nurses. The questionnaire was translated from the English version to the local language and again back to the English version to keep it consistent. The data was then collected by selecting a convenient time for study participants which was during night and day time.
The preventive practice was measured using three "yes/no" questions: 1) Do you use condom always for any sexual intercourse even with your constant partner? 2) Do you share any sharpen materials with anyone else around you? 3) Did you tested for HIV in the last three months?

Finally, female sex workers, who answered "yes" for all of the above 3 questions were considered as having good preventive practice of HIV (17). However, those who answered "no" for at least one of the questions were considered as having poor preventive practice of HIV.

The data was cleaned, coded and entered into Epi data version 3.1 software and exported into SPSS version 20.0 for analysis. Descriptive analysis was done, and the results were displayed in the form of texts and frequency tables. Then, model fitness and correlation between independent variables were checked.

Binary logistic regression analysis was done using the odds ratio with a $95 \%$ Confidence interval to identify the factors associated with the preventive practice of HIV among FSWs. Finally, multivariable logistic regression analysis was performed to control possible potential confounders and to identify the independent predictors of preventive practice of HIV among FSWs. The statistical significance level was declared at a P-value $<0.05$.

\section{RESULTS}

Socio-demographic characteristics of participants: A total of 393 female sex workers were participated in the study with the response rate of $94 \%$. The mean age of the study participants was 22.6 years $\pm 2.6 \mathrm{SD}$. Of the total participants, $132(33.6 \%)$ attended secondary education and above, 245(62.3\%) were single, 239(60.8\%) migrated from other urban areas and 380(96.7\%) were categorized as hotel/bar-based female sex workers (Table 1). 
Table 1: Socio-demographic characteristics of FSWs in Afar region, Northeast Ethiopia, 2018.

\begin{tabular}{|c|c|c|}
\hline Variables & Number of FSWs & Percent \\
\hline \multicolumn{3}{|l|}{ Age } \\
\hline $15-24$ & 328 & 83.4 \\
\hline$>=25$ & 65 & 16.5 \\
\hline \multicolumn{3}{|l|}{ Educational level } \\
\hline cannot read \& write & 30 & 7.6 \\
\hline Only read \& write & 118 & 30 \\
\hline Elementary & 113 & 28.8 \\
\hline Secondary \& above & 132 & 33.6 \\
\hline \multicolumn{3}{|c|}{ Marital status before being FSWs } \\
\hline Single & 245 & 62.3 \\
\hline Married & 148 & 37.7 \\
\hline \multicolumn{3}{|l|}{ Residence before joining FSW } \\
\hline Urban & 239 & 60.8 \\
\hline Rural & 154 & 39.2 \\
\hline \multicolumn{3}{|l|}{ Working environment } \\
\hline Established based/Bar & 380 & 96.7 \\
\hline Home based & 13 & 3.3 \\
\hline
\end{tabular}

HIV/AIDS preventive practice of FSWs: The overall preventive practice of HIV/AIDS among female sex workers was $61.1 \%(95 \% \mathrm{CI}: 56 \%-$ $65.9 \%)$. In the study, more than half $(53.2 \%)$ of FSWs had sexual contact with unknown persons who can pay. This was followed by having sexual contact with long distance track drivers $(25.4 \%)$. Moreover, 245(62.3\%) of the participants reported that they always use condom for every sexual contact including their permanent clients. Besides, $353(89.8 \%)$ of the FSW never share sharp materials with anyone else around them, and 265 (67.4\%) of the study participants reported that they were tested for HIV in the last three months. Regarding substance use, $88.1 \%$ of the participants were alcohol drinkers, $56.7 \%$ were khat chweres, $11.2 \%$ were cigarette smokers and $5.6 \%$ were shisha users (Table 2).

Factors associated with HIV/AIDS preventive practice among FSWs: Bivariate and multivariable analyses were performed to determine the factors associated with preventive practice of HIV/AIDS among female sex workers. Variables with P-value $<0.25$ were entered into the multivariable logistic regression model. The model fitness and correlation between independent variables were checked.

After adjustment was made for covariates, being single $[\mathrm{AOR}=2.57$ : 95\% CI 1.06, 6.21: $\mathrm{P}<0.05]$ and origin of urban residence before being sex worker $[\mathrm{AOR}=3.26$ : $95 \%$ CI $1.25,8.54$ : $\mathrm{P}<0.05]$ were enhancing factors for the preventive practice of HIV among FSWs. However, being illiterate $[\mathrm{AOR}=0.133: 95 \%$ CI $0.032,0.557$ : $\mathrm{P}<0.01]$, being young $(15-24$ years of age $)$ [AOR=0.065: 95\% CI 0.021,0.196: $\mathrm{P}<0.001]$, being alcohol drinker $[\mathrm{AOR}=0.104: 95 \% \mathrm{CI} 0.026,0.417$ : $\mathrm{P}<0.01]$, being smoker $[\mathrm{AOR}=0.096: 95 \% \mathrm{CI}$ 0.022, 0.414: $\mathrm{P}<0.01]$ and lack of aware of mode of transmission of HIV [AOR $=0.08: 95 \%$ CI 0.03 , 0.22: $\mathrm{P}<0.001]$ were the hindering factors of preventive practice of HIV among FSWs (Table 3). 
Table 2: HIV/AIDS preventive practice of FSWs in Afar region, Northeast Ethiopia, 2018

\begin{tabular}{|c|c|c|c|}
\hline List of Variables & Category of variables & Frequency & Percent (\%) \\
\hline \multirow{5}{*}{$\begin{array}{l}\text { With whom you had } \\
\text { sex in the last month }\end{array}$} & Unknown person who can pay & 209 & 53.2 \\
\hline & Student & 7 & 1.8 \\
\hline & Merchant & 32 & 8.1 \\
\hline & Alcohol drunker & 45 & 11.5 \\
\hline & long distance track driver & 100 & 25.4 \\
\hline \multirow{2}{*}{$\begin{array}{l}\text { Use Condom in the last one } \\
\text { month }\end{array}$} & Yes & 345 & 87.8 \\
\hline & No & 48 & 12.2 \\
\hline \multirow[t]{5}{*}{ Reason of condom use } & To avoid pregnancy & 44 & 11.2 \\
\hline & To prevent HIV/AIDS & 321 & 81.7 \\
\hline & Prevent other STI & 40 & 10.2 \\
\hline & By friend interest & 18 & 4.5 \\
\hline & Unknown reason & 3 & 0.8 \\
\hline \multirow{6}{*}{$\begin{array}{l}\text { Condom use in the recent } \\
\text { sexual practice } \\
\text { Always Use condom for } \\
\text { every sexual contact } \\
\text { including boyfriend } \\
\text { Use sharp materials alone }\end{array}$} & Yes & 374 & 95.2 \\
\hline & No & 19 & 4.8 \\
\hline & Yes & 245 & 62.3 \\
\hline & No & 148 & 37.7 \\
\hline & Yes & 353 & 89.8 \\
\hline & No & 40 & 10.2 \\
\hline \multirow{2}{*}{$\begin{array}{l}\text { Tested for HIV in the last } \\
3 \text { months }\end{array}$} & Yes & 265 & 67.4 \\
\hline & No & 128 & 32.6 \\
\hline \multirow{4}{*}{$\begin{array}{l}\text { Know HIV/AIDS } \\
\text { prevention methods }\end{array}$} & Having constant customer & 29 & 7.4 \\
\hline & Avoid alcohol drinking & 60 & 15.3 \\
\hline & Properly use condom & 262 & 66.7 \\
\hline & Avoid sharp materials sharing & 42 & 10.7 \\
\hline \multirow[t]{2}{*}{ Alcohol use } & Yes & 346 & 88.1 \\
\hline & No & 47 & 11.7 \\
\hline \multirow[t]{2}{*}{ Cigarette smoking } & Yes & 44 & 11.2 \\
\hline & No & 349 & 88.8 \\
\hline \multirow[t]{2}{*}{ Shisha Smoking } & Yes & 22 & 5.6 \\
\hline & No & 371 & 94.4 \\
\hline \multirow[b]{2}{*}{ Khat chewing } & Yes & 223 & 56.7 \\
\hline & No & 170 & 43.3 \\
\hline
\end{tabular}


Table 3: Factors associated with preventive practice of HIV/AIDS among FSWs in Afar region, Northeast

Ethiopia, 2018

\begin{tabular}{|c|c|c|c|c|c|}
\hline \multirow{2}{*}{$\begin{array}{l}\text { List of Predictor } \\
\text { variables }\end{array}$} & \multirow{2}{*}{$\begin{array}{l}\text { Category of } \\
\text { variables }\end{array}$} & \multicolumn{2}{|c|}{ Preventive practice } & \multirow[t]{2}{*}{ COR (95\% CI) } & \multirow[t]{2}{*}{ AOR (95\% CI } \\
\hline & & Yes $(\%)$ & No $(\%)$ & & \\
\hline \multirow[t]{2}{*}{ Age } & $15-24$ & $\begin{array}{l}194 \\
(49.4)\end{array}$ & $134(34.1)$ & $\begin{array}{l}0.598 \\
(0.335,1.066)\end{array}$ & $0.065(0.021,0.196)^{* * *}$ \\
\hline & $>=25$ & $46(11.7)$ & $19(4.8)$ & 1.00 & 1.00 \\
\hline \multirow[t]{2}{*}{ Marital status } & Single & $\begin{array}{l}171 \\
(43.5)\end{array}$ & $74(18.8)$ & $2.64(1.73,4.04)$ & $2.57(1.06,6.21)^{*}$ \\
\hline & Married & $69(17.6)$ & $79(20.1)$ & 1.00 & 1.00 \\
\hline \multirow{4}{*}{$\begin{array}{l}\text { The completed } \\
\text { Education level } \\
\text { attended }\end{array}$} & Can't read \& write & $9(2.3)$ & $21(5.3)$ & $\begin{array}{l}0.316(0.134 \\
0.742)\end{array}$ & $\begin{array}{l}0.133(0.032 \\
0.557)^{* *}\end{array}$ \\
\hline & Can read \& write & $78(19.8)$ & $40(10.2)$ & $1.43(0.86,2.40)$ & $0.524(0.21,1.33)$ \\
\hline & Primary school & $77(19.6)$ & $36(9.2)$ & $1.57(0.93,2.66)$ & $2.65(0.074,9.47)$ \\
\hline & $\begin{array}{l}\text { Secondary \& } \\
\text { above }\end{array}$ & $76(19.3$ & $56(14.2)$ & 1.00 & 1.00 \\
\hline \multirow[t]{2}{*}{$\begin{array}{l}\text { Residence before } \\
\text { being FSWs }\end{array}$} & Urban & $\begin{array}{l}165 \\
(42.0)\end{array}$ & $74(18.8)$ & $2.35(1.54,3.57)$ & $3.26(1.25,8.54)^{*}$ \\
\hline & Rural & $75(19.1)$ & $79(20.1)$ & 1.00 & 1.00 \\
\hline \multirow[t]{2}{*}{ Work place } & Hotel/bar based & $\begin{array}{l}236 \\
(60.1)\end{array}$ & $\begin{array}{l}144 \\
(36.6)\end{array}$ & $3.68(1.11,12.19)$ & $0.45(0.03,6.47)$ \\
\hline & Home based & $4(1.0)$ & $9(2.3)$ & 1.00 & 1.00 \\
\hline Currently Drink & No & $33(8.4)$ & $14(3.6)$ & 1.00 & \\
\hline Alcohol & Yes & $\begin{array}{l}207 \\
(52.7)\end{array}$ & $\begin{array}{l}139 \\
(35.4)\end{array}$ & $0.632(0.326,1.22)$ & $0.104(0.026,0.417)^{* *}$ \\
\hline \multirow[t]{2}{*}{$\begin{array}{l}\text { Currently use } \\
\text { Shisha }\end{array}$} & No & $230(58.5$ & $\begin{array}{l}141 \\
(35.9)\end{array}$ & 1.00 & 1.00 \\
\hline & Yes & $10(2.5)$ & $12(3.1)$ & $\begin{array}{l}0.511(0.215 \\
1.213)\end{array}$ & $0.254(0.056,1.154)$ \\
\hline \multirow[t]{2}{*}{$\begin{array}{l}\text { Currently } \\
\text { Cigarette smoking }\end{array}$} & No & $\begin{array}{l}228 \\
(58.0)\end{array}$ & $\begin{array}{l}121 \\
(30.8)\end{array}$ & 1.00 & 1.00 \\
\hline & Yes & $12(3.1)$ & $32(8.1)$ & $0.199(0.099,0.40)$ & $0.096(0.022,0.414)^{* *}$ \\
\hline \multirow{2}{*}{$\begin{array}{l}\text { Aware of HIV } \\
\text { mode of } \\
\text { transmission }\end{array}$} & No & $33(8.4)$ & $\begin{array}{l}114 \\
(29.0)\end{array}$ & $0.055(0.033,0.91)$ & $0.08(0.03,0.22)^{* * *}$ \\
\hline & Yes & $\begin{array}{l}207 \\
(52.7)\end{array}$ & $39(9.9)$ & 1.00 & 1.00 \\
\hline
\end{tabular}

$*=\mathrm{P}<0.05, * *=\mathrm{P}<0.01, * * *=\mathrm{P}<0.001, \mathrm{COR}=$ Crude Odds Ratio, $\mathrm{AOR}=$ Adjusted Odds ratio, $\mathrm{CI}=$ Confidence interval

\section{DISCUSSION}

The World Health Organization has categorized the world population into highly vulnerable and less vulnerable population towards HIV/AIDS (2).
Female sex workers are one of the vulnerable segment of population (9) though they are given little attention in developing countries including Ethiopia. The studies conducted before this study measured the HIV preventive practice among

DOI: http://dx.doi.org/10.4314/ejhs.v30i1.7 
female sex workers using scores above the median scores or above the $75^{\text {th }}$ percentiles. However, this study measured the preventive practice using the 100 percent "yes" response of three common questions adapted from different literatures $(8,17,29$,$) conducted in Ethiopia. Thus, this$ community-based cross-sectional study was conducted to assess the preventive practice and associated factors of HIV/AIDS among female sex workers. Besides, HIV preventive practice among female sex workers is among the key interventions designed to minimize the risk of infection among themselves and the general population.

This study revealed that the self-reported preventive practice of HIV/AIDS among female sex workers was $61.1 \%$ (95\% CI 56.2\%-65.9\%). This finding is higher than a study conducted in Northwest Ethiopia (54.7\%) (14), a communitybased cross-sectional study conducted in Dessie town, Northeast Ethiopia (54.8\%) (17) study carried out in Mongolia (49.1\%) (18), and a study done in Southwestern Ethiopia (41.5\%) (19). The discrepancy could be explained by the difference in the number of questions used during the measurement of the outcome variable and the difference in cut-off points to determine the level of preventive practice. Moreover, it might be due to variations of socio-cultural characteristics of the study participants.

However, the level of HIV/AIDS preventive practice among female sex workers (FSWs) in this study was found lower than te one in a study conducted in Nepalian FSWs (82.2\%) (21) and a study done among Chile FSWs (93.4\%) (22). This can be explained by differences in the sociodemographic characteristics like most of the study participants were single and nearly half of the participants had attended primary and above education levels in the current study. This in turn increases the awareness of the female sex workers upon HIV/AIDS preventive practice.

Female sex workers (FSWs) who had not yet attended formal education had $87 \%$ less preventive practice of HIV compared to those attended secondary and above education level. This finding is similar to a study done in south west Ethiopia (19). This could be explained by differences in level of awareness. Hence, the lower the level of awareness, the lower the preventive practice of HIV/AIDS.

The preventive practice of HIV among single female sex workers was 2.6 times higher compared to those who were married. This is in line with the study done in Ghana (31). This could be justified by the fact that single female sex workers have been confident enough to use HIV protective methods compared to married female sex workers. Besides, women who had history of marriage may not properly use the protective methods since they have exposure to unprotected sexual contacts with their husbands or anyone else. Hence, single women are less at risk for HIV infection than married women.

The FSWs who were in the young age group (15-24 years of age) had $93.5 \%$ less preventive practice of HIV compared to those in the age group of 25 years and above. This is in line with a systematic review of FSW studies conducted in lowto-middle income countries (4). This could be explained by the fact that people in the young age group might be involved in many misbehaviors, risky sexual acts and other hindering factors of preventive practice of HIV compared to adult people.

The level of preventive practice of HIV among FSWs who resided in urban areas before beginning sex work was 3 times greater compared to those in rural areas. This finding is similar with a literature review done in sub-Saharan Africa (24). This might be due to lack of access to HIV prevention and health information, health service access and socicultural variations among women wo originated from rural settings compared to the female sex workers who originated from the urban community.

Female sex workers who were alcohol drinkers had $89.6 \%$ less preventive practice of HIV compared to those who were not alcohol drinkers. Moreover, cigarette smoker FSWs had 90.4\% less preventive practice of HIV than non-smokers. This finding is in line with a review study done in different regions of the world (26), a study done in Indian FSWs (27), a study done in Mombasa, Kenya (28) and a study done in Gondar, Ethiopia (29). This could be explained by the fact that heavy alcohol drinking and cigarette smoking can undermine consistent condom use. This is because alcohol can interfere with decision making of FSWs and their clients regarding sexual decision making, condom

DOI: http://dx.doi.org/10.4314/ejhs.v30i1.7 
negotiation and their correct use. Hence, using either combined or separated substance may lead to forgetting of consistent condom use and increase the risk of acquisition of HIV and other sexually transmitted infection among risky groups and the larger population. A systematic review of empirical findings on alcohol use and sexual risk behaviors for HIV/AIDS in SSA established that alcohol consumption has a positive correlation with increased risk for HIV/AIDS.

FSWs who had no awareness about the mode of transmission of HIV had 92\% less preventive practice of HIV compared to those who had awareness of the mode of transmission. This finding is supported by the study conducted in South Africa (30) and the one done in Iran (25). This can be because women who do not know about HIV mode of transmission can have poor preventive practice compared to women who knew the mode of transmission of HIV. As a result, these female sex workers could be at higher risk of acquiring HIV and the potential transmitters of HIV into the general population.

Limitations of the study: Firstly, it was conducted by employing non-probable sampling technique. Hence, it is not representative of the general population. In addition, the study also shares the limitation of cross-sectional study design.

In conclusion, the overall level of preventive practice of HIV among female sex workers is still suboptimal compared to other studies. The current study has identified different hindering factors of preventive practice of HIV among FSWs such as being illiterate, being alcohol drinker, lack awareness of the mode of HIV transmission and being in the young age group. Therefore, the regional health sectors and stakeholders should give due attention to addressing the reproductive health of female sex workers and to providing HIV prevention methods. Female sex workers should avoid risky behaviors such as excessive alcohol drinking. Additional analytical study designs triangulated with qualitative methods are recommended.

Ethical considerations and consent for participants: Ethical clearance was obtained from ethical review board (ERB) of Samara University, College of Medical and Health Sciences with Ref.
№. CMHS/38/35/18. Then, permission letter was written from Regional Health Bureau to the four town administrative. Written informed consent was obtained from each study participants during data collection. The study participants were given the right to refuse, stop or withdraw at any time from the interview. And also, the participants were informed that they will not be financially benefited by their participation and will not loss any benefit due to their refusal. Confidentiality was maintained by keeping records in secured manner and avoiding personal identifiers.

\section{ACKNOWLEDGMENTS}

The authors thank Samara University, College of Medical and Health Sciences, for its ethical review process. The authors also thank supervisors, data collectors, study participants and all other individuals for their contributions throughout this study.

\section{REFERENCES}

1. Pinsky L, Douglas PH. HIV and AIDS: Columbia University; 2017.

2. WHO. Implementing Comprehensive HIV/STI Programs with Sex Workers. Geneva, Switzerland: 2013.

3. Population survey international Ethiopia (PSI/E). Hotspot town survey mapping, 2014

4. Baral S, Beyrer C, Muessig K, et al. Burden of HIV among female sex workers in low-income and middle-income countries: A systematic review and meta-analysis. Lancet Infect Dis. 2012 Jul; 12(7):538-49. doi: 10.1016/S14733099(12)70066-X.

5. World Health Organization. Global update on the health sector response to HIV, 2014. Geneva, Switzerland: WHO, 2014.

6. Central Statistical Agency [Ethiopia].. Ethiopia Demographic and Health Survey 2016. Addis Ababa, Ethiopia, Maryland, USA: CSA and ICF; 2017.

7. Ethiopian Public Health Institute [EPHI]. HIV prevalence among female sex workers in selected towns of Ethiopia. Addis Ababa Ethiopia, 2014 
8. Federal HIV/AIDS Prevention and Control Office [FHAPCO], PSI. Country Progress Report on HIV/AIDS Response, 2014. Addis Ababa-Ethiopia: Federal HIV/AIDS Prevention and Control Office, 2014.

9. Thomas B. Sexual and reproductive health and HIV/AIDS risk perception in the Malawi tourism industry. Malawi Med J. 2010, 21(2): 75-80. doi: $10.4314 / \mathrm{mmj} . v 21 \mathrm{i} 2.44554$

10. Nwauche, C. A., \& Akani, C. I. An assessment of high risk sexual behaviour and HIV transmission among migrant oil workers in the Niger Delta area of Nigeria. Nigerian Journal of Clinical Practice. 2006, 9(1), 48-51.

11. Udoh, I. A. Oil, migration, and the political economy of HIV/AIDS prevention in Nigeria's Niger Delta. International Journal of Health Services: Planning, Administration, Evaluation, 2013; 43(4): 681-9.

12. Muula, A., \& Twizelimana, D. HIV and AIDS risk perception among sex workers in semiurban Blantyre, Malawi. Tanzania Journal of Health Research 2015; 17 (3). Doi: http://dx.doi.org/10.4314/thrb.v17i3.5.

13. Nwauche, C. A., \& Akani, C. I. An assessment of high risk sexual behaviour and HIV transmission among migrant oil workers in the Niger Delta area of Nigeria. Nigerian Journal of Clinical Practice. 2016;12(1):48-51.

14. Tamene MM, Tessema GA, Beyera GK. Condom utilization and sexual behavior of female sex workers in Northwest Ethiopia: A cross-sectional study. The Pan African medical journal. 2015;21 doi:10.11604/pamj.2015.21.50.6009

(50):

15. World Health Organization. Consolidated guidelines on HIV prevention, diagnosis, treatment and care for key populations. World Health Organization, 2014.

16. Soliman C, El Taher Z, Abed El Sattar A, Shawky S, Feyisetan B,Oraby D, et al. [Abstract]. Key findings of Bio-BSS among highrisk groups in the Middle East, Egypt case study. 2008. XVII International AIDS Conference. Abstract no. TUPE 0273.

17. Woday A, Menber Y, Yimam F, Melese N, Dagne S. The Preventive Practice of and Associated Factors of HIV/AIDS among
Female Sex Workers in Dessie Town, Northeast Ethiopia. J Women's Health Care. 2017; 7: 425.

18. Munkhbaatar S, Aumakhan B, Jantsansengee B, Azyei I, Sanjaajamts Z, Badrakh J, et al. HIV and sexually transmitted infection-related risks among female sex workers in Mongolia: second-generation surveillance survey, 20112012. Sexually transmitted infections. 2014; 90(6):463-8.

19. Gemechu Kejela LO, Yadeta Dessie, Direslgne Misker. Comprehensive HIV/AIDS knowledge level among out-of-school youths in Wayu Tuka district, Western Ethiopia. European Journal of Preventive Medicine. 2015; 3(1):11-6.

20. Chersich, M. F., Luchters, S., Ntaganira, I., Gerbase, A., Lo, Y.-R., Scorgie, F., \& Steen, R. Priority interventions to reduce HIV transmission in sex work settings in subSaharan Africa and delivery of these services. Journal of the International AIDS Society. 2013; 16: 17980.

21. Etl. SB. Knowledge and attitude on HIV-AIDS and Practice of Sexual Behavior among Female Sex Workers: a pilot study in Jhapa, Nepal. IOSR Journal of Dental and Medical Sciences. 2014; 13(11): 46-52.

22. Barrientos JE, Bozon M, Ortiz E, Arredondo A. Assessment of HIV prevalence, AIDS Knowledge and condom use among female sex workers in Santiago Chile. Cadernosde Saude publica. 2007; 23(8):1777-84. DOI: 10.1590/S0102-311X2007000800004

23. Ding GW, Hsi JH, Liu HX, Su YY, Wang JJ, Bai J, et al. HIV-infected female sex workers' high risk behavior and attitude changes in Kaiyuan City, Yunnan Province, China. Biomedical and environmental sciences. BES. 2014; 27(6):444-52.

24. World Health Organization. Preventing HIV among sex workers in sub-Saharan Africa: a literature review. 2013.

25. Khajehkazemi R, Haghdoost A, Navadeh S, Setayesh H, Sajadi L, Osooli M, et al. Risk and vulnerability of key populations to HIV infection in Iran; knowledge, attitude and practises of female sex workers, prison inmates and people who inject drugs. Sexual health. 2014; 11 (6): 568-74.

DOI: http://dx.doi.org/10.4314/ejhs.v30i1.7 
26. Carael, M., Slaymaker, E., Lyerla, R., \& Sarkar, S. Clients of sex workers in different regions of the world: hard to count. Sexually transmitted infections. 2006; 82(3):26-33.

27. Samet JH, Pace CA, Cheng DM, Coleman S, Bridden C. Alcohol use and sex risk behaviours among HIV-infected female sex workers (FSWs) and HIV-infected male clients of FSWs in India. AIDS \& Behavior. 2010; 14(Suppl. 1): S74-83.

28. Bengtson AM, L'Engle K, Mwarogo P, King'ola $\mathrm{N}$. Levels of alcohol use and history of HIV testing among female sex workers in Mombasa, Kenya. AIDS care. 2014;26(12):1619-24.

29. Megabiw BA, T. Comprehensive knowledge, attitude and practice of street adults towards human immunodeficiency virus/acquired immune deficiency syndrome (HIV/AIDS) in Northwest Ethiopia. Journal of AIDS and HIV Research. 2013; 5(6: 181-187.

30. Dunkle, K. L., Beksinska, M. E., Rees, V. H., Ballard, R. C., Htun, Y., \& Wilson, M. L. Risk factors for HIV infection among sex workers in Johannesburg, South Africa. International Journal of STD \& AIDS. 2005;16(3):256-61

31. Adu-Oppong, A., Grimes, R. M., Ross, M. W., Risser, J., \& Kessie, G. Social and behavioral determinants of consistent condom use among female commercial sex workers in Ghana. AIDS Education and Prevention: Official Publication of the International Society for AIDS Education. 2007; 19(2): 160-72.

DOI: http://dx.doi.org/10.4314/ejhs.v30i1.7 